\title{
Ramping up of SARS CoV-2 testing for the diagnosis of COVID- 19 to better manage the next phase of pandemic and reduce the mortality in India
}

\author{
Senthilkumar Natesan ${ }^{1,3}$ (D) $^{-}$Ragini Bhatia $^{1} \cdot$ Aarthi Sundararajan $^{1} \cdot$ \\ Kuldeep Dhama ${ }^{2} \cdot$ Yashpal S. Malik ${ }^{4} \cdot$ Kranti Vora $^{1}$
}

Received: 31 May 2020/Accepted: 30 July 2020/Published online: 8 August 2020

(C) Indian Virological Society 2020

\begin{abstract}
The coronavirus disease 2019 (COVID-19) pandemic is caused by the severe acute respiratory syndrome coronavirus-2, a new member of the Coronavirus family. The virus was first identified in Wuhan, China, where the epidemic originated. The viral genome was sequenced and a real time reverse transcription polymerase chain reaction assay was developed and used for the detection of virus. Different countries took different approaches for the diagnosis of COVID-19. Some countries prioritized extensive testing for COVID-19 at a very early phase of the pandemic whereas other countries took a long time to build the testing capacity and to implement the testing extensively. The assay design formats were available in the public domain and thereby allowing researchers to replicate them to make diagnostic kits. Consequently, several antigen or antibody-based diagnostic tests were also developed for the diagnosis of COVID-19. However, there were some validation and regulatory challenges while bringing these assays into the market. During the course of the pandemic, it became clear that the countries which
\end{abstract}

Senthilkumar Natesan

snatesan@iiphg.org

$\triangle$ Kuldeep Dhama

kdhama@rediffmail.com

1 Indian Institute of Public Health Gandhinagar, Lekawada, Gandhinagar, Gujarat 382042, India

2 Division of Pathology, ICAR-Indian Veterinary Research Institute, Izatnagar, Bareilly, Uttar Pradesh 243122, India

3 Biomac Life Sciences Pvt Ltd, Sargasan, Gandhinagar, Gujarat 382421, India

4 Division of Biological Standardization, ICAR-Indian Veterinary Research Institute, Izatnagar, Bareilly, Uttar Pradesh 243 122, India implemented testing at an early stage of the pandemic were capable of controlling the spread more effectively than those that implemented them at later stages. As several countries implemented a lockdown for controlling the spread of the virus, it is critical to build the testing capability to meet the extensive need of testing while exiting the lockdown. Testing and isolation of positive cases are the most effective ways of preventing the spread of virus and gradually returning life back to normality.

Keywords COVID-19 - Laboratory testing - RT-qPCR . Serological test · SARS CoV-2 - Antigen · Antibody . Diagnosis

\section{Introduction}

The coronavirus disease 2019 (COVID-19) is a disease caused by severe acute respiratory syndrome coronavirus- 2 (SARS-CoV-2), a member of the Coronavirus family and a newly emerging zoonotic agent $[1,10]$. These are enveloped positive-strand RNA viruses isolated from bats, which share a sequence homology with isolates from humans, suggesting that bats are the natural hosts and reservoirs [26, 9]. This disease was first identified in Wuhan, China, in patients with symptoms of pneumonia who were not responding to antibiotics; it is characterized by the occurrence of fever, dry cough, and shortness of breath. On March 13th 2020, the World Health Organization (WHO) declared COVID-19 to be a pandemic [5]. At present, the world is witnessing a surge in cases; millions of people were detected with the disease and many lost their lives. A recently published systematic review and meta-analysis has highlighted that COVID-19 has resulted in a huge burden on healthcare facilities and has proved to 
be fatal in patients with comorbidities. The study also revealed that admission in intensive care units was required for approximately $20 \%$ of COVID-19 infected polymorbid patients, and hospitalization was associated with a case fatality rate of $>13 \%$ [26]. Preventive measures, such as increased testing, isolation of positive cases and tracing their contacts, and implementation of lockdowns have considerably controlled the spread of the virus. However, after relaxation of the lockdown, it is critical to implement extensive testing and continue to take preventive measures while returning to normality. Because this virus is spreading globally, there is an urgent need for countries to keep human resources, infrastructure, and testing facilities ready to carry out large number of tests for diagnosing COVID-19 as the demand is going to be increasing in the next phase of the pandemic. It is imperative to take immediate action to curb the rise in deaths through community spread by making tests widely available and performing an adequate number of tests to prevent the spread of COVID-19 while exiting the lockdown restrictions and returning to normality.

\section{Role of laboratory testing}

Laboratory testing for identification of diseases is critical to save the lives of patients and to contain the spread of viruses during epidemics or pandemics. In a typical clinical setting in any hospital, $70-80 \%$ of the clinical decisions to treat patients are taken based on laboratory tests [32]. However, laboratories account for a small part of hospital operations, and the amount spent on laboratory tests is only around $3-5 \%$ of the total hospital expenditure, which is insignificant compared to the amount spent on pharmacies and other operations. It is clear that the laboratories and tests are not lucrative from the financial point of view to a hospital; nevertheless, they are critical from the perspective of managing patients and saving lives [17]. In addition, testing is neglected when dealing with diseases for which there is no specific treatment available.

Laboratory diagnosis and confirmation of suspected cases is very important to implement preventive measures to control the spread of an infectious agent during an epidemic. Consequently, the management of an epidemic depends on the test results. As a single positive case can trigger a huge mobilization of resources to contain the spread. It may be from isolation of the positive case, tracing their contacts, testing and isolating them in quarantine, etc. During the early phase of COVID-19 spread in Wuhan, China has moved promptly and decisively, and has ensured massive laboratory testing, early identification of cases, isolation of all positive cases, contact tracing, and quarantine [35]. Moreover, in the entire Chinese population, mobility was at a near standstill, with social distancing implemented on a large scale. However, despite the massive transmission rates and implementation of extreme measures within the country, China neglected the risk of spread of the pandemic outside its borders and undermined its global impact.

Countries with no or few confirmed cases and only limited local transmission need to invest in aggressive testing for COVID-19 in all cases of atypical pneumonias as well as those of acute respiratory infection. Contact tracing should be stringent and legally enforced [13]. Singapore was successful in containing COVID-19 with measures like laboratory testing, containment and contact tracing, and interruption of new transmission chains without lockdown or social disruption [20]. Extensive testing of suspected cases is critical for a public health system to optimize utilization of resources and take proper control measures to contain the spread of the virus. Additionally, testing provides the initial evidence for a case and helps the public health system take decisions based on evidence. Hence, the availability of reliable cost-effective diagnostic tests is very important. Although testing is the first step to confirm suspected cases or monitor contacts of confirmed cases, it is not being effectively implemented in several countries during the ongoing pandemic. Development of cost-effective viral genome detection systems, such as the real time reverse transcription polymerase chain reaction (RT-qPCR) assay, and their validation is critical to implement testing successfully. Validation of existing serological tests, including those that have been developed by commercial organizations, and establishment of biobanks and serum panels of well characterized COVID-19 sera to support such efforts is also necessary [4].

South Korea has taken the approach to extensively test individuals with innovative voluntary testing option for people in drive-through testing stations and has also offered home collection of samples, after which the results are shared through text messages [21]. Traditional sample collection in laboratories or hospitals increases the risk of people infecting each other. Outdoor sample collection minimizes contamination of public health facilities and also reduces the risk of healthcare professionals acquiring the infection during sample collection. The sincerity displayed by the South Korean population in coming forward, getting themselves tested, isolating or quarantining themselves if found positive, and seeking help from the health system indicates a great sense of responsibility for protecting fellow citizens. With timely action taken to manage the epidemic with extensive testing, South Korea managed the COVID-19 pandemic very well with minimum mortality and also averted a major lockdown. The preparedness and execution of an appropriate laboratory testing plan by South Korea provided evidence that high causalities and a 
huge burden on the public health system could be prevented with a proper approach to testing and isolation of the positive cases and people who have come in contact with them [19]. Taiwan also endorsed, mobilized, and adopted specific approaches for case identification, containment, and resource allocation to protect the public health during the COVID-19 crisis. Taiwan is another country that enhanced COVID-19 detection by proactively seeking out patients with severe respiratory symptoms as per the information from the National Health Insurance database and retesting those who were found to be negative for influenza [34]. The Swiss government also recognized the importance of the testing strategy and strengthened it further to control COVID-19 [28]. Nevertheless, it is also important to understand why similar approaches were not implemented in other countries facing the same crisis.

\section{Inadequate testing}

One of the reasons why an extensive testing approach was not implemented in several countries, including India, was the lack of adequate testing kits and reagents. The tests were used judiciously in only symptomatic cases during the initial phase, according to strict guidelines, and only in selected public testing facilities. Following the onset of the COVID-19 outbreak in Wuhan, the virus was isolated, sequenced, and the entire genome sequence was publicly made available through the NCBI nucleotide sequence database. As soon as the SARS-CoV-2 genome sequence was made available, the first RT-PCR test protocol was made freely available from the Berlin-Charité laboratory through the WHO website (https://www.who.int/publica tions $/ \mathrm{m} /$ item/molecular-assays-to-diagnose-covid-19-summ ary-table-of-available-protocols). Chinese researchers have also developed a qPCR-based molecular diagnostic assay and used this standardized assay to test patients across China. Reports on these assays were also published in reputed journals such as the New England Journal of Medicine. The United States also isolated and characterized the virus after the first case was detected $[16,14]$. Therefore, it is now easy to reproduce these tests. As a preparedness measure to detect COVID-19 cases, countries should stock upon RNA extraction reagents or kits, have sufficient quantities of primers and probes synthesized for large-scale testing, and procure sufficient quantities of qPCR master mixes. These individual components can be combined and kits can be prepared within a short period of time, as there are several commercial companies supplying such reagents. Besides, there are several public and private organizations capable of producing such kits in countries such as India. Although private organizations may be hesitant to develop such kits, considering the regulatory complexities involved in kit development, governmentfunded organizations can develop these kits quickly, validate them, and get them approved by the required regulatory agencies, as accomplished by China when the virus was first identified. This process can assist in creating the much-needed testing and screening capacity in India and other countries and reduce the dependency on imported kits. There is no shortage of infrastructure and equipment in the private and public sector for COVID-19 testing in many countries. For carrying out COVID-19 testing, a laboratory should follow the Biosafety Level-2 (BSL-2) or higher guidelines to protect personnel as well as the environment [33]. It is recommended that good microbiological laboratory practices and universal precautions must be followed in all laboratories where primary specimens (sputum samples; throat, nasopharyngeal, and oropharyngeal swabs; and stool samples) that may contain SARS-CoV-2 are handled. While working with suspected patients' samples, laboratory personnel should be supervised by staff who are competent in handling infectious agents and are well-versed in the related standard procedures [24]. The equipment required for sample preparation and testing includes a biosafety cabinet class-II, microcentrifuge, PCR machine, qPCR machine, freezer, and refrigerator. These instruments are easily available in any life science research institution and molecular diagnostic laboratory. India has a very welltrained workforce for carrying out these PCR-based tests. They carry out similar tests for HIV, Hepatitis-B, and Hepatitis-C routinely. Most of the laboratories may not have centralized facilities equipped with expensive automated sample preparation and testing systems; however, they have all the basic instruments to carry out molecular diagnostic testing. Another reason for inadequate testing may be due to the high cost of the available tests, and it may not have been possible for the public health system to implement such testing on a large scale. The costs of imported commercial kits are very high; however, if these tests are developed in laboratories within a country, it is considerably cheaper and easily affordable for use in largescale testing programs. If a country decides to make its own kits, it can be done in matter of days by roping in research institutions as well as public and private sectors to develop such diagnostic kits within a stipulated time period provided that robust test validation and QC/QA are in place. The validation of these kits can prove that tests developed in-house are as good as imported commercial kits. The development of a diagnostic kit for COVID-19 should be executed on an emergency basis with the help of financial support. The scientists can also perform a cost analysis of the test kits and investigate the impact of testing. The protocols used for testing of COVID-19 in different countries in Europe are available in the public domain through WHO (https://www.who.int/publications/m/item/ 
molecular-assays-to-diagnose-covid-19-summary-table-ofavailable-protocols). As far as the development of an RTqPCR diagnostic kit is concerned, it is only an adaptation of previously validated reagents and methods. If the performance of a newly developed kit is comparable with that of an already approved kit, it can be used widely for the diagnosis of COVID-19, however, obtaining an approval from the regulatory agency is still needed to commercialize the kit.

\section{Testing for COVID-19}

The most common method of testing used for diagnosing COVID-19 is the RT-qPCR technique, which is based on the detection of viral RNA in the nasopharyngeal, oropharyngeal, or bronchoalveolar lavage samples. There are alternative approaches to diagnose COVID-19, but these are not widely used. A simple PCR technique that involves only primers can also be used for the detection of coronavirus. Unlike the qPCR technique, which requires an expensive qPCR machine and fluorescent probes, the conventional PCR requires a much cheaper thermal cycler, horizontal electrophoresis system, and gel documentation system. After performing the conventional PCR, samples can be run on an agarose gel, stained with ethidium bromide, and visualized under UV-light. When the amplified products are of the expected size, the positivity of a sample can be determined. Alternatively, the amplified products can be sent for sequencing and the results can be confirmed based on nucleotide sequences. This simple PCR technique combined with Sanger sequencing will be cheaper than RT-qPCR and the data can be analyzed by determining the sequence of the virus at the single nucleotide level, which may be more specific. A desirable approach would be to test the samples in any BSL-2 laboratory having molecular diagnostic infrastructure by recruiting locally available personnel and reporting results in the shortest possible turnaround time. In India, there are several laboratories in each city and state capable of performing such tests using different options such as conventional PCR, RT-qPCR, sanger sequencing, next generation sequencing, etc. A few selected laboratories at the state level can be used for confirmatory testing by performing quality checks on the laboratories carrying out COVID-19 testing by periodically cross-testing samples.

A more in-depth understanding of the virus, beyond the method for its detection and diagnosis, is important to understand its origin and evolution. It is important to understand if the virus causing an epidemic in a particular country is exactly the same as the one that originated in Wuhan or whether it has mutated to a new phenotype exhibiting a higher or lower virulence. In low resource setting, the variable regions of the virus can be amplified and sequenced using Sanger sequencing which is cheaper compared to next generation sequencing. The variable region sequence of the local isolates can be aligned with isolates from the initial outbreak in China and viruses from other countries to understand the evolution of this virus as a result of acquiring mutations. Next, the aligned sequences can be used to build a phylogenetic tree to understand the origin and/or evolution of the local isolates. Simple SNPs markers characterizing the main SARS-CoV-2 circulating clades are made available through the GISAID initiative (https://www.gisaid.org/). Sequencing the genomic regions including those SNPs can be a simple and cost-effective method to compare local strains with strains circulating globally. Highly advanced next generation sequencing technologies based on the Illumina, Thermo Scientific, or Oxford nanopore platforms can help us sequence the entire genome of hundreds of virus samples in a single run within a short period of time. The next generation sequencing facilities are available in many public and private sector laboratories. Such facilities and manpower need to be mobilized in a well-planned manner to help us to understand the behavior and characteristics of the virus. The whole genome sequence of SARS-CoV-2 from patients can help in understanding the virus origin, evolution, and virulence more accurately than studying only the variable regions. The instruments required for such testing are very expensive; however, their use during this critical time will justify their cost.

\section{Antigen- or antibody-based testing of COVID-19}

Several diagnostic tests based on SARS-CoV-2 specific $\mathrm{IgG} / \mathrm{IgM}$ antibody detection (rapid antibody test) have been developed. Recently, in India, the Indian Council of Medical Research (ICMR) issued the first advisory on 4th April, 2020 to use these rapid antibody tests along with RTqPCR assays for assessing COVID-19 spread in areas comprising clusters, containment zones, and other large gatherings (Fig. 1, source: ICMR). In addition, 7 commercially available antibody-based rapid tests have been validated at the National Institute of Virology, Pune, and were found to be satisfactory at the time [6]. However, on 27 April, 2020, a revised advisory on rapid antibody testing was issued by ICMR stating that few kits evaluated in field conditions demonstrated variations in sensitivity. Therefore, there is a need to develop and also validate high quality antibody-based testing of COVID-19. Although the virus-specific antibody diagnostic assay cannot be used to directly detect acute COVID-19 infection, it has several novel applications critical to the assessment of the spread of the disease in a given population. SARS-CoV-2 specific 


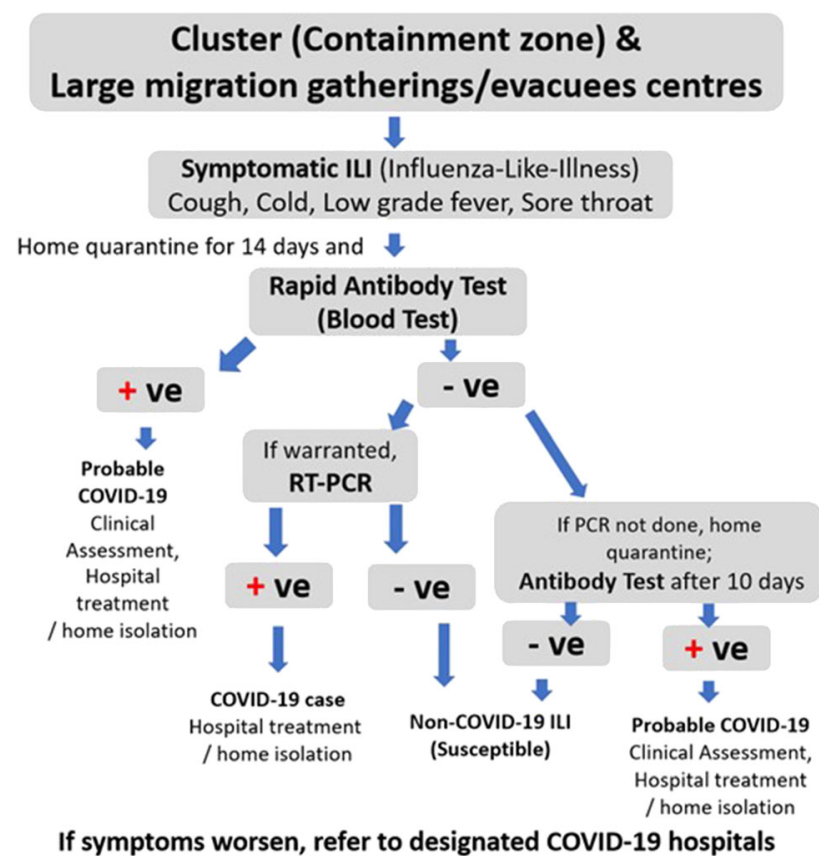

Fig. 1 ICMR issued advisory for testing strategy during the early stage of COVID-19 epidemic in India ( Source: Information of testing strategies for antibody rapid test issued on 4 April 2020 (ICMR)

IgG detection could serve as a qualitative and quantitative diagnostic assay with which sero surveys could be performed in hot spots to determine the rate of infection and fatality, including contact tracing of individuals suspected of virus exposure weeks ago. With respect to public health, these tests are critical to assess the number of asymptomatic cases, which have been recently increasing in China and other parts of the world. It is also believed that children are largely asymptomatic carriers [25], and this type of antibody testing strategy will be helpful in assessing the rate of infection and formulating public health policies for restricting their interaction with vulnerable population. Besides, these tests can help in assessing the efficacy of vaccines in clinical trials. Furthermore, a quantitative assessment of SARS-CoV-2 specific IgG could be used for the identification of individuals who have a strong antibody response who could help in the development of convalescent serum therapy. The assay will also help determine the number of immune healthcare workers who can then be selectively deployed in COVID-19 associated high-risk regions. Although there have been isolated cases involving re-infection, an experimental study involving re-infection of rhesus macaques with SARSCoV-2 demonstrated that there was no recurrence of COVID-19, suggesting that a protective effect is conferred by the primary infection [3]. Along these lines, it has been shown in a long-term prospective cohort study in China, which involved healthcare workers belonging to a clustered outbreak of SARS infection in 2002-03, that SARS-CoV specific IgG persist for a very long time (12 years) following primary infection [15]. Moreover, a primary immune response in relation to a mild-to-moderate COVID-19 infection has been recently published, demonstrating increased antibody-secreting cells, activated $\mathrm{T}$ cells, and virus-specific IgG and IgM antibodies in blood for at least 7 days before full symptomatic recovery $[30,18]$. Although the virus-specific antibody response is critical for virus clearance, in the case of people who died of SARS infection, increased neutralizing spike specific IgG antibodies have been shown to be key mediators of acute lung injury through the induction of pro-inflammatory responses in wound healing macrophages [23]. These studies highlight the need to assess the scope and kinetics of immune responses in cases involving COVID-19 infections of varying severity in order to develop a new antibody-based testing strategy for predicting the disease outcome.

In a study involving 610 hospitalized patients from Wuhan, patients clinically diagnosed with COVID-19 showed a high false negative rate when real-time RTqPCR-based testing of SARS-CoV-2 was performed. It was also reported that the results of virus detection using RTqPCR at different time points were highly variable in the same patients during the course of the disease, which suggested the requirement of a standardized protocol for sample collection, sample transportation, testing by RTqPCR, and serological diagnosis for SARS-CoV-2 [22]. A study done on a cohort of 1014 patients demonstrated that patients who were initially RT-qPCR negative showed positive chest CT scans for pneumonia and later tested positive by RT-qPCR through repeated swab testing [2]. In addition, test sensitivity (with respect to SARS-CoV-2) largely varies depending on the type and number of samples collected from the same individual. The method of collection of nasopharyngeal swabs, viral load in the sample, assessment of samples at different stages of progression of the disease, and delay in transportation may affect the results [12]. The test is also time-consuming with a possibility of obtaining false negative reports. A study also investigated the estimation of the active viral load in the upper respiratory tract that can help make decisions regarding containment strategies. Therefore, immunological assays, such as enzyme-linked immunosorbent assays (ELISAs), which directly detect viral antigens, should be developed [7], and their translation into point-of-care (POC) testing can become an invaluable tool for diagnosis of COVID-19 [31].

To design an immunoassay to detect the virus directly, for example, using sandwich ELISA, it is vital to select the appropriate antigen to be detected. For example, the spike protein is a key protein for virus entry into the host cells that interacts with angiotensin-converting enzyme-2, 
thereby generating strong neutralizing antibodies. It is reported that specific regions of this protein are unique to each coronavirus [36]; therefore, if designed accurately, there are minor chances of cross-reactivity with other coronaviruses and false positive cases can be reduced. For example, a recombinant full-length spike protein (with modifications for increasing stability) and the associated receptor binding domain of SARS-CoV-2 have been shown to be successful antigens for the detection of virus-specific antibodies in sera derived from COVID-19 patients [27].

In addition to the spike protein, the internal nucleocapsid protein, which is the most abundant protein present in the virus, is an alternative candidate antigen when designing an ELISA [29]. Overall, immunoassays that can be translated into POC assays to detect either an antigen or antibody in throat swabs would be efficient and yield immediate assessment of COVID-19 infection in patients under quarantine and in hotspots showing high transmission-cum-infectivity rates.

The non-governmental organization FIND, which works on the development and research of various diagnostic tests, has prepared a list of the rapid antibody and antigen tests being used by different nations and those that are under evaluation. Five out of 17 antigen-detection rapid diagnostic tests and 27 out of 53 antibody-detection (serological) RDTs are being included in the first round of evaluation. Seven serological ELISAs have also been selected for evaluation [11].

\section{Impact of testing in different countries}

The way South Korea managed the COVID epidemic with massive testing and isolation of positive cases and tracing their contacts and taking preventive measures successfully averted the huge morbidity and mortality. South Korea saw surge of cases in the month of February and used Korean Model, which includes a regime of "trace, test, treat" to curb the spread and mortality of the COVID-19 virus. This model proved how necessary testing is to track cases, the ones in contact with the cases and then to quarantine them at the right time. They were able to flatten the curve without putting a nationwide lockdown in place. They took draconian steps to limit the disease and the affected. From January itself they were prepared with the test kits that helped in responding at the earliest. Nearly 20,000 tests were done each day. Korea is now in full control on the spread of the disease. They took strict measures at the international borders with screening of passengers and isolating them if suspected. Extensive testing was done in high risk areas and clusters. From the time of confirmation of virus genome in Wuhan, Korean medical teams and biocompanies developed new testing kits with high speed and accuracy. People who had symptoms or needed to be tested, got the test within minutes at 'drive-through' or 'walkthrough' testing centers and could receive the results next day through text message. Their quick response with clear objective of testing and isolating the positive cases came from their previous experiences of handling epidemics such as SARS and Bird flu in the past. This approach helped to achieve lowest mortality rate and lowest number of cases. Korea is now prepared for second wave of infections which presumably could be more intense. As per South Korea CDC, South Korea tested 16.64 per thousand people; 852,876 in total as of 27 May 2020 [8].

Germany also took prompt actions with vigorous testing of the suspected patients. It stayed ahead of other European countries by testing widely and keeping the mortality as low as possible. Germany enacted on time making diagnostic kits readily available. As per Robert Koch Institute, Germany tested 47.18 per thousand people; $3,952,971$ in total as of 24 May 2020 [8].

The United States had some problems with the initial testing kits and diagnostic tests could not be performed widely in the initial stage of the disease. But it managed to ramp up its testing capacity to reach a level where it could estimate the spread of the disease. Therefore, testing at the right time was the key to control the pandemic. According to COVID Tracking Project, the U.S. tested 45.04 per thousand people; $14,907,041$ in total as of 26 May 2020 [8].

Italy has also done testing on a large scale now at stage 2 and stage 3 of the disease, it is difficult to control mortalities especially when a major proportion of the population is above 60 years of age. Italy had conducted 37.88 tests per thousand people; 2,290,551 in total as of 27 May 2020 [8].

India needs to escalate its testing capacity so that it can track the disease efficiently. Indian laboratories and companies should up the testing kit production and testing capacity. Testing kits should be made readily available and help from other nations should be considered. This window of opportunity should not be lost. As per ICMR, India has conducted tests in total 2.27 per thousand people; $3,126,119$ in total as of 26 May 2020 [8]. Figure 2 shows the total tests for COVID-19 per thousand people conducted by different countries as of 29th May 2020.

Figure 3 shows the total confirmed COVID-19 deaths per million rolling 7 day average in various countries as of 27th May [8]. The graphs also show a correlation between testing and mortality. South Korea among the abovementioned countries has the minimum mortality. Then comes Germany with lowest mortality rate among other European nations. United States and Italy are witnessing the highest mortalities due to the delay in testing. This data clearly shows that the countries that conducted most 


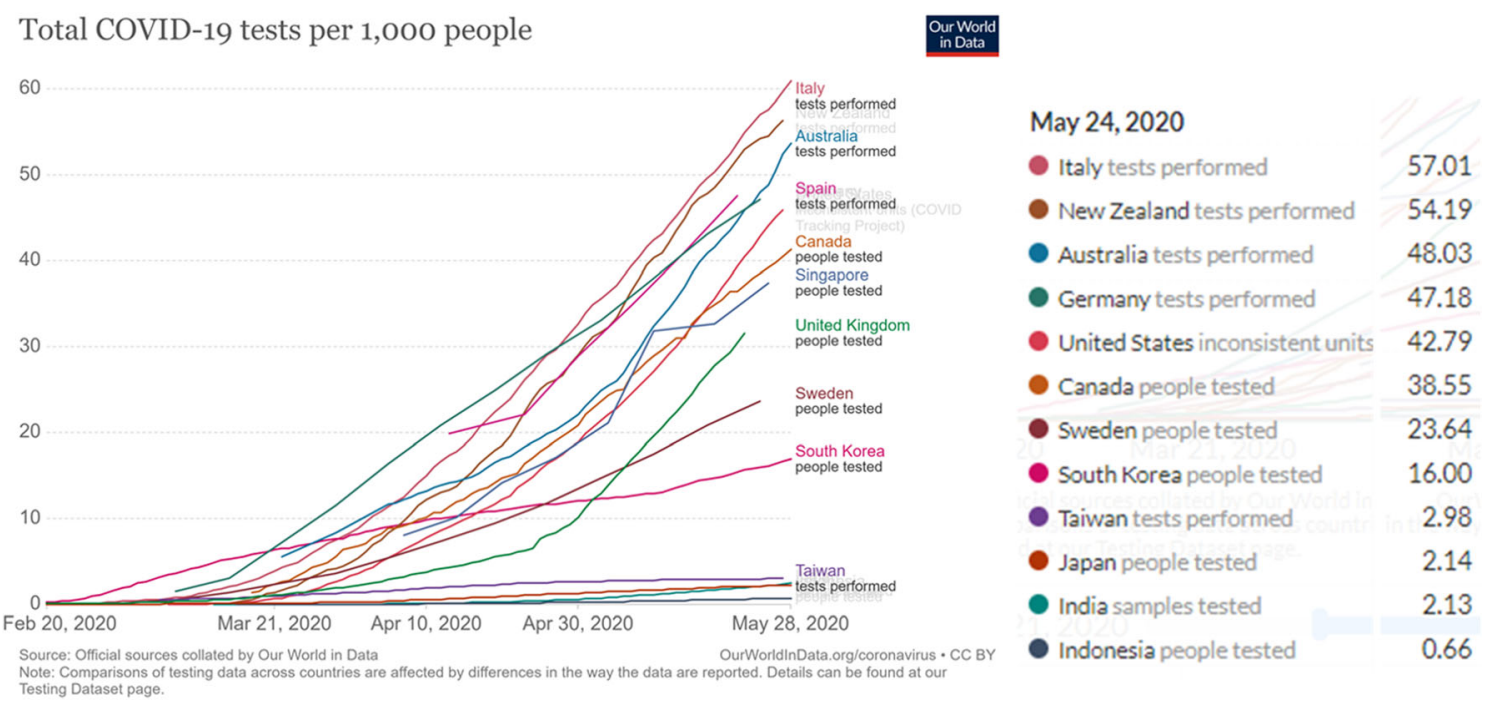

Fig. 2 Total COVID-19 tests performed per thousand people in various countries as of 29th May 2020

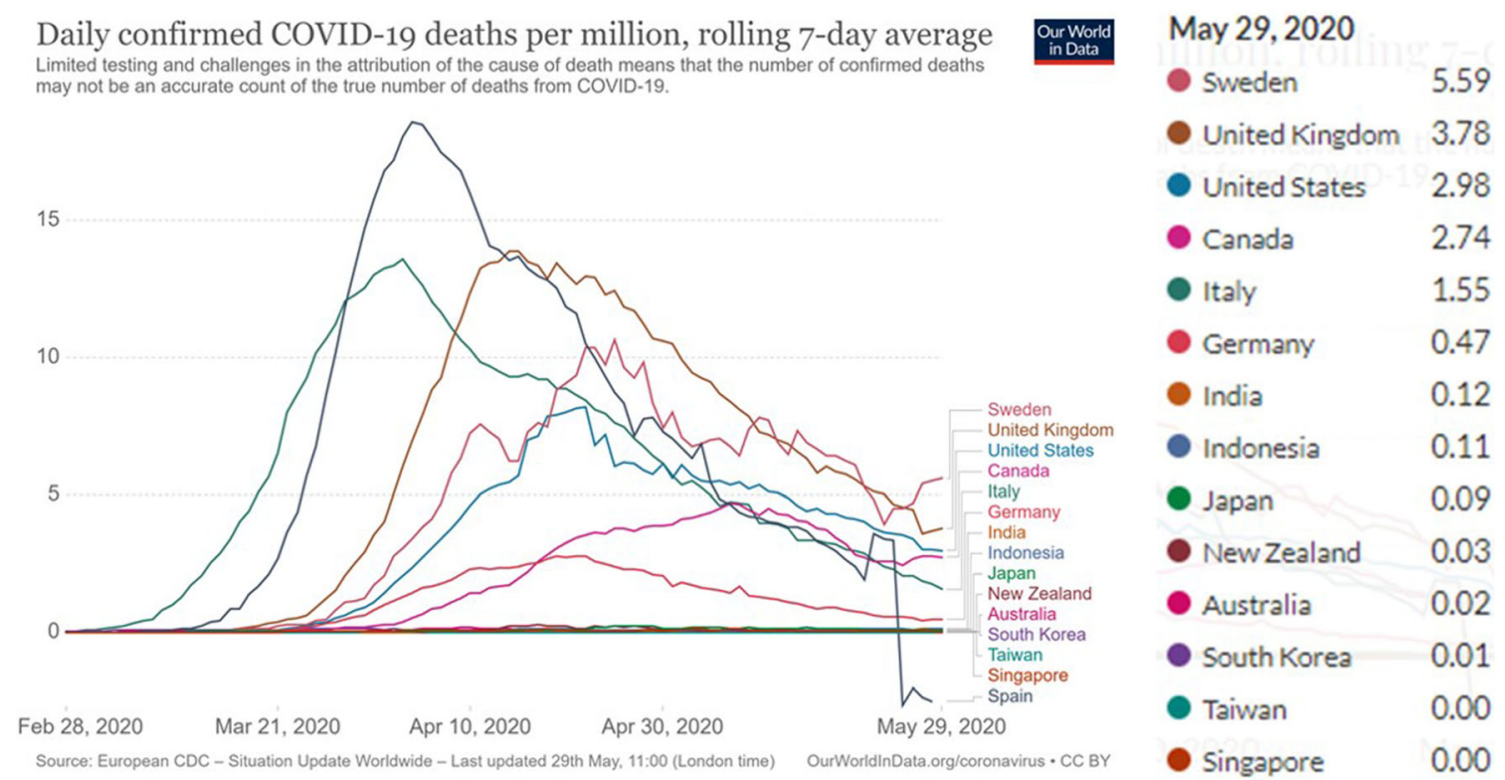

Fig. 3 Daily confirmed COVID-19 deaths per million rolling 7 day average in various countries as of 28th May 2020

number of tests at the right time were able to curb the community transmission and therefore precluded the mortalities and morbidities. Therefore, quick and robust action can save millions of lives.

Considering the present scenario, the media is doing a commendable job of updating the general public, the government is doing its best to prevent the spread of infection, and diagnostic labs are doing their best to diagnose this infection. However, very limited efforts have been undertaken to understand the origin and evolution of the virus and its antigenic changes by making optimum use of advanced technologies such as next generation sequencing. Scientists with expertise in specific areas such as virology, protein modelling, bioinformatics, genomics, and immunology in various research institutions need to collaborate with each other to come up with tangible solutions in terms of diagnostics, therapeutics, and vaccine development. Viral RNA, viral cDNA, and virus samples from COVID-19 patients have to be biobanked and shared with laboratories that can carry out further research in a collaborative manner. Research and diagnostic laboratories should have the capacity to carry out a large number of tests in the next phase of the COVID-19 pandemic, especially if the number of cases increase following the relaxation of the lockdown. The manufacturers and suppliers of COVID-19 diagnostic kits and reagents also need to 
manufacture and stock up to meet long-term requirements as the virus may circulate in the population for a prolonged period of time. Testing, tracing, and treating are the three critical steps to curb the spread of the disease and reduce mortality.

\section{Concluding remarks}

We can therefore conclude that adequate and timely testing is the right way to curb down mortality rates in the COVID-19 pandemic. It is imperative for the governments of all countries to keep the healthcare system updated on the latest developments in the field of testing for the diagnosis of COVID-19. New information on the testing of symptomatic and asymptomatic cases will give an opportunity to flatten the curve as soon as possible by taking evidence-based control measures and save more lives. All countries need to continue to adopt pandemic control measures based on increased testing; accurate confirmation of cases; strict isolation of confirmed cases, contact tracing, and enforcement of quarantine for all contacts. As the entire public health protection measure begins with testing, countries need to increase their testing capacity by including more research and diagnostic laboratories to carry out COVID-19 testing as well as by accelerating the production of test kits and reagents to meet future requirements. As the virus may circulate and continue to infect new individuals, the success of controlling the spread of COVID-19 following post-lockdown period may depend on the testing strategies. Adopting proper testing strategy will help returning to normality by reducing the mortality and preventing the emergence of second wave of new infections.

Acknowledgements All the authors acknowledge and thank their respective Institutes and Universities.

Funding This compilation is a review article written by its authors and required no substantial funding to be stated.

\section{Compliance with ethical standards}

Conflict of interest All authors declare that there exist no commercial or financial relationships that could, in any way, lead to a potential conflict of interest.

\section{References}

1. Ahmad T, Khan M, Haroon MTH, Nasir S, Hui J, Bonilla-Aldana DK, Rodriguez-Morales AJ. COVID-19: zoonotic aspects. Travel Med Infect Dis. 2020. https://doi.org/10.1016/j.tmaid.2020. 101607.

2. Ai T, Yang Z, Hou H, Zhan C, Chen C, Lv W, Tao Q, Sun Z, Xia L. Correlation of chest CT and RT-PCR testing in coronavirus disease 2019 (COVID-19) in China: a report of 1014 cases. Radiology. 2020;26:200642. https://doi.org/10.1148/radiol. 2020200642.

3. Bao L, Deng W, Gao H, Xiao C, Liu J, Xue J, Lv Q, Liu J, Yu P, Xu Y, Qi F, Qu Y, Li F, Xiang Z, Yu H, Gong S, Liu M, Wang G, Wang S, Song Z, Liu Y, Zhao W, Han Y, Zhao L, Liu X, Wei Q, Qin C. Lack of reinfection in rhesus macaques infected with SARS-CoV-2. bioRxiv. 2020. https://doi.org/10.1101/2020.03. 13.990226.

4. Bedford J, Enria D, Giesecke J, Heymann DL, Ihekweazu C, Kobinger G, Lane HC, Memish Z, Oh MD, Sall AA, Schuchat A, Ungchusak K, Wieler LH, WHO Strategic, and Technical Advisory Group for Infectious Hazards. COVID-19: towards controlling of a pandemic. Lancet. 2020;395(10229):1015-8. https://doi.org/10.1016/S0140-6736(20)30673-5.

5. Bhatia R, Chaudhary R, Khurana SK, Tiwari R, Dhama K, Gupta VK, Singh RK, Natesan S. Strengthening of molecular diagnosis of SARS-CoV-2/COVID-19 with a special focus on India. J Pure Appl Microbiol. 2020;14(suppl 1):789-98. https://doi.org/10. 22207/JPAM.14.SPL1.16.

6. COVID-19. Indian Council of Medical Research I Government of India. 2020. https://icmr.nic.in/content/covid-19. Accessed 25 Mar 2020.

7. Carter LJ, Garner LV, Smoot JW, Li Y, Zhou Q, Saveson CJ, Sasso JM, Gregg AC, Soares DJ, Beskid TR, Jervey SR, Liu C. Assay techniques and test development for COVID-19 diagnosis. ACS Cent Sci. 2020;6(5):591-605. https://doi.org/10.1021/acs centsci.0c00501.

8. Coronavirus disease (COVID-19)—statistics and research-our world in data. 2020. https://ourworldindata.org/coronavirus. Accessed 24 Mar 2020

9. Dhama K, Patel SK, Pathak M, Yatoo MI, Tiwari R, Malik YS, Singh R, Sah R, Rabaan AA, Bonilla-Aldana DK, RodriguezMorales AJ. An update on SARS-CoV-2/COVID-19 with particular reference to its clinical pathology, pathogenesis, immunopathology and mitigation strategies. Travel Med Infect Dis. 2020;30:101755. https://doi.org/10.1016/j.tmaid.2020. 101755

10. El Zowalaty ME, Järhult JD. From SARS to COVID-19: a previously unknown SARS- related coronavirus (SARS-CoV-2) of pandemic potential infecting humans-call for a One Health approach. One Health. 2020;24(9):100124. https://doi.org/10. 1016/j.onehlt.2020.100124.

11. FIND evaluation update: SARS-CoV-2 immunoassays-FIND. 2020. https://www.finddx.org/covid-19/sarscov2-eval-immuno/. Accessed 20 Apr 2020.

12. False negatives and reinfections: the challenges of SARS-CoV-2 RT-PCR testing. 2020. https://asm.org/Articles/2020/April/FalseNegatives-and-Reinfections-the-Challenges-of. Accessed 17 May 2020.

13. Fisher D, Wilder-Smith A. The global community needs to swiftly ramp up the response to contain COVID-19. Lancet. 2020;395(10230):1109-10. https://doi.org/10.1016/S0140-6736 (20)30679-6.

14. Guan WJ, Ni ZY, Hu Y, Liang WH, Ou CQ, He JX, Liu L, Shan H, Lei CL, Hui DSC, Du B, Li LJ, Zeng G, Yuen KY, Chen RC, Tang CL, Wang T, Chen PY, Xiang J, Li SY, Wang JL, Liang ZJ, Peng YX, Wei L, Liu Y, Hu YH, Peng P, Wang JM, Liu JY, Chen Z, Li G, Zheng ZJ, Qiu SQ, Luo J, Ye CJ, Zhu SY, Zhong NS, China Medical Treatment Expert Group for Covid-19. Clinical characteristics of coronavirus disease 2019 in China. N Engl J Med. 2020;382(18):1708-20. https://doi.org/10.1056/NEJMoa20 02032.

15. Guo X, Guo Z, Duan C, Chen Z, Wang G, Lu Y, Li M, Lu J. Long-term persistence of $\mathrm{IgG}$ antibodies in SARS-CoV infected 
healthcare workers. MedRxiv. 2020. https://doi.org/10.1101/ 2020.02.12.20021386.

16. Harcourt J, Tamin A, Lu X, Kamili S, Sakthivel SK, Wang L, et al. Isolation and characterization of SARS-CoV-2 from the first US COVID-19 patient. bioRxiv. 2020. https://doi.org/10.1101/ 2020.03.02.972935.

17. Interpretation of laboratory results. 2020. https://acutecaretesting. org/en/articles/interpretation-of-laboratory-results. Accessed 17 May 2020.

18. Jacofsky D, Jacofsky EM, Jacofsky M. Understanding antibody testing for COVID-19. J Arthroplasty. 2020;S0883-5403(20):30 442-3. https://doi.org/10.1016/j.arth.2020.04.055.

19. Jeong GH, Lee HJ, Lee KH, Han YJ, Yoon S, Lee J, et al. Epidemiology and important lessons from the coronavirus disease 2019 (COVID-19) outbreak in South Korea. SSRN Electron J. 2020. https://doi.org/10.2139/ssrn.3559575.

20. Lee D, Lee J. Testing on the move: South Korea's rapid response to the COVID-19 pandemic. Transp Res Interdiscip Perspect. 2020;5:100111. https://doi.org/10.1016/j.trip.2020.100111.

21. Lee D, Lee J. Testing on the move South Korea's rapid response to the COVID-19 pandemic. Transp Res Interdiscip Perspect. 2020;21:100111. https://doi.org/10.1016/j.trip.2020.100111.

22. Li Y, Yao L, Li J, Chen L, Song Y, Cai Z, Yang C. Stability issues of RT-PCR testing of SARS-CoV-2 for hospitalized patients clinically diagnosed with COVID-19. J Med Virol. 2020. https://doi.org/10.1002/jmv.25786.

23. Liu L, Wei Q, Lin Q, Fang J, Wang H, Kwok H, Tang H, Nishiura K, Peng J, Tan Z, Wu T, Cheung KW, Chan KH, Alvarez X, Qin C, Lackner A, Perlman S, Yuen KY, Chen Z. Anti-spike IgG causes severe acute lung injury by skewing macrophage responses during acute SARS-CoV infection. JCI Insight. 2019;4(4):e123158. https://doi.org/10.1172/jci.insight. 123158.

24. Mourya DT, Sapkal G, Yadav PD, Belani SK, Shete A, Gupta N. Biorisk assessment for infrastructure and biosafety requirements for the laboratories providing coronavirus SARS-CoV-2/ (COVID-19) diagnosis. Indian J Med Res. 2020;151(2 \& 3):172-6. https://doi.org/10.4103/ijmr.IJMR_763_20PMID: 32242878 .

25. Qiu H, Wu J, Hong L, Luo Y, Song Q, Chen D. Clinical and epidemiological features of 36 children with coronavirus disease 2019 (COVID-19) in Zhejiang, China: an observational cohort study. Lancet Infect Dis. 2020;S1473-3099(20):30198-205. https://doi.org/10.1016/S1473-3099(20)30198-5.

26. Rodriguez-Morales AJ, Cardona-Ospina JA, Gutiérrez-Ocampo E, Villamizar-Peña R, Holguin-Rivera Y, Escalera-Antezana JP, Alvarado-Arnez LE, Bonilla-Aldana DK, Franco-Paredes C, Henao-Martinez AF, Paniz-Mondolfi A, Lagos-Grisales GJ, Ramírez-Vallejo E, Suárez JA, Zambrano LI, Villamil-Gómez WE, Balbin-Ramon GJ, Rabaan AA, Harapan H, Dhama K, Nishiura H, Kataoka H, Ahmad T, Sah R, Latin American
Network of Coronavirus Disease 2019-COVID-19 Research (LANCOVID-19). Clinical, laboratory and imaging features of COVID-19: A systematic review and meta-analysis. Travel Med Infect Dis. 2020. https://doi.org/10.1016/j.tmaid.2020.101623.

27. SARS-CoV-2 reagents for your COVID-19 research-bio-connect. 2020. https://www.bio-connect.nl/covid-19-reagents/cnt/ page/6570. Accessed 17 May 2020.

28. Salathé M, Althaus CL, Neher R, Stringhini S, Hodcroft E, Fellay J, Zwahlen M, Senti G, Battegay M, Wilder-Smith A, Eckerle I, Egger M, Low N. COVID-19 epidemic in Switzerland: on the importance of testing, contact tracing and isolation. Swiss Med Wkly. 2020;19(150):w20225. https://doi.org/10.4414/smw.2020. 20225.

29. Surjit M, Lal SK. The SARS-CoV nucleocapsid protein: a protein with multifarious activities. Infect Genet Evol. 2008;8(4):397405. https://doi.org/10.1016/j.meegid.2007.07.004.

30. Thevarajan I, Nguyen THO, Koutsakos M, Druce J, Caly L, van de Sandt CE, Jia X, Nicholson S, Catton M, Cowie B, Tong SYC, Lewin SR, Kedzierska K. Breadth of concomitant immune responses prior to patient recovery: a case report of non-severe COVID-19. Nat Med. 2020;26(4):453-5. https://doi.org/10.1038/ s41591-020-0819-2.

31. Udugama B, Kadhiresan P, Kozlowski HN, Malekjahani A, Osborne M, Li VYC, Chen H, Mubareka S, Gubbay JB, Chan WCW. Diagnosing COVID-19: the disease and tools for detection. ACS Nano. 2020;14(4):3822-35. https://doi.org/10.1021/ acsnano.0c02624.

32. Uncovering revenue sources through transformation of the hospital lab. 2020. https://www.beckershospitalreview.com/finance/ uncovering-revenue-sources-through-transformation-of-the-hospi tal-lab.html. Accessed 17 May 2020.

33. WHO. Laboratory biosafety manual - third edition. 2020. https:// www.who.int/csr/resources/publications/biosafety/WHO_CDS_ CSR_LYO_2004_11/en/. Accessed 24 Mar 2020.

34. Wang CJ, Ng CY, Brook RH. Response to COVID-19 in Taiwan: big data analytics, new technology, and proactive testing. JAMA. 2020. https://doi.org/10.1001/jama.2020.3151.

35. Wilder-Smith A, Freedman DO. Isolation, quarantine, social distancing and community containment: pivotal role for old-style public health measures in the novel coronavirus $(2019-\mathrm{nCoV})$ outbreak. J Travel Med. 2020;27(2):taaa020. https://doi.org/10. 1093/jtm/taaa020.

36. Xu X, Chen P, Wang J, Feng J, Zhou H, Li X, Zhong W, Hao P. Evolution of the novel coronavirus from the ongoing Wuhan outbreak and modeling of its spike protein for risk of human transmission. Sci China Life Sci. 2020;63(3):457-60. https://doi. org/10.1007/s11427-020-1637-5.

Publisher's Note Springer Nature remains neutral with regard to jurisdictional claims in published maps and institutional affiliations. 